\title{
Assessing snow extent data sets over North America to inform and improve trace gas retrievals from solar backscatter
}

\author{
Matthew J. Cooper ${ }^{1}$, Randall V. Martin ${ }^{1,2}$, Alexei I. Lyapustin ${ }^{3}$, and Chris A. McLinden ${ }^{4}$ \\ ${ }^{1}$ Department of Physics and Atmospheric Science, Dalhousie University, Halifax, Nova Scotia, Canada \\ ${ }^{2}$ Harvard-Smithsonian Center for Astrophysics, Cambridge, Massachusetts, USA \\ ${ }^{3}$ NASA Goddard Space Flight Center, Greenbelt, Maryland, USA \\ ${ }^{4}$ Air Quality Research Division, Environment and Climate Change Canada, Toronto, Ontario, Canada
}

Correspondence: Matthew J. Cooper (cooperm2@ dal.ca)

Received: 12 January 2018 - Discussion started: 24 January 2018

Revised: 1 May 2018 - Accepted: 3 May 2018 - Published: 22 May 2018

\begin{abstract}
Accurate representation of surface reflectivity is essential to tropospheric trace gas retrievals from solar backscatter observations. Surface snow cover presents a significant challenge due to its variability and thus snowcovered scenes are often omitted from retrieval data sets; however, the high reflectance of snow is potentially advantageous for trace gas retrievals. We first examine the implications of surface snow on retrievals from the upcoming TEMPO geostationary instrument for North America. We use a radiative transfer model to examine how an increase in surface reflectivity due to snow cover changes the sensitivity of satellite retrievals to $\mathrm{NO}_{2}$ in the lower troposphere. We find that a substantial fraction $(>50 \%)$ of the TEMPO field of regard can be snow covered in January and that the average sensitivity to the tropospheric $\mathrm{NO}_{2}$ column substantially increases (doubles) when the surface is snow covered.

We then evaluate seven existing satellite-derived or reanalysis snow extent products against ground station observations over North America to assess their capability of informing surface conditions for TEMPO retrievals. The Interactive Multisensor Snow and Ice Mapping System (IMS) had the best agreement with ground observations (accuracy of $93 \%$, precision of $87 \%$, recall of $83 \%$ ). Multiangle Implementation of Atmospheric Correction (MAIAC) retrievals of MODIS-observed radiances had high precision (90\% for Aqua and Terra), but underestimated the presence of snow (recall of $74 \%$ for Aqua, $75 \%$ for Terra). MAIAC generally outperforms the standard MODIS products (precision of $51 \%$, recall of $43 \%$ for Aqua; precision of $69 \%$, recall of $45 \%$ for Terra). The Near-real-time Ice and Snow Ex-
\end{abstract}

tent (NISE) product had good precision (83\%) but missed a significant number of snow-covered pixels (recall of $45 \%$ ). The Canadian Meteorological Centre (CMC) Daily Snow Depth Analysis Data set had strong performance metrics (accuracy of $91 \%$, precision of $79 \%$, recall of $82 \%$ ). We use the $F$ score, which balances precision and recall, to determine overall product performance $(F=85 \%, 82(82) \%$, $81 \%, 58 \%, 46$ (54) \% for IMS, MAIAC Aqua (Terra), CMC, NISE, MODIS Aqua (Terra), respectively) for providing snow cover information for TEMPO retrievals from solar backscatter observations. We find that using IMS to identify snow cover and enable inclusion of snow-covered scenes in clear-sky conditions across North America in January can increase both the number of observations by a factor of 2.1 and the average sensitivity to the tropospheric $\mathrm{NO}_{2}$ column by a factor of 2.7.

\section{Introduction}

Satellite observations of solar backscatter are widely used as a source of information on atmospheric trace gases (Richter and Wagner, 2011). These observations have provided valuable information on vertical column densities of $\mathrm{O}_{3}, \mathrm{NO}_{2}$, $\mathrm{SO}_{2}, \mathrm{CO}, \mathrm{HCHO}, \mathrm{CH}_{4}$, and other important trace gases in the troposphere (Fishman et al., 2008). Satellite observations of trace gases have been used to assess air quality (Duncan et al., 2014; Martin, 2008) and to gain insight into atmospheric processes including emissions (Streets et al., 2013), lifetimes (Beirle et al., 2011; Fioletov et al., 2015; de Foy et al., 2015; 
Valin et al., 2013), and deposition (Geddes and Martin, 2017; Nowlan et al., 2014). The utility of these observations is dependent on their quality, and thus ensuring retrieval accuracy is essential.

Previous studies have found that retrieved $\mathrm{NO}_{2}$ vertical column densities are highly sensitive to errors in assumed surface reflectance (Boersma et al., 2004; Lamsal et al., 2017; Martin et al., 2002). Much of this error sensitivity results from observation sensitivity to trace gases in the lower troposphere. The observation sensitivity is accounted for in the air mass factor (AMF) conversion of observed line-ofsight "slant columns" to vertical column densities. Uncertainties in surface reflectance are a significant contributor to AMF uncertainty.

Existing reflectivity climatologies (e.g. Kleipool et al., 2008; Koelemeijer et al., 2003; Liang et al., 2002; Herman and Celarier, 1997) do not represent snow cover well, since the statistical methods to exclude reflective clouds from the climatologies also exclude variable snow cover. Correspondingly, surface snow may be mistaken for cloud, leading to errors in cloud fraction and pressure estimates used in trace gas retrievals (Lin et al., 2015; O'Byrne et al., 2010; Vasilkov et al., 2017). Therefore, snow cover is particularly challenging to retrievals. Misrepresenting surface snow cover can lead to large errors $(20-50 \%)$ in retrieved $\mathrm{NO}_{2}$ columns over broad regions with seasonal snow cover (O'Byrne et al., 2010). For this reason, observations over snow are often omitted or flagged as unreliable to avoid potential errors. This limits the ability of satellite retrieved data sets to offer adequate temporal and spatial sampling in winter months. Additionally, over highly reflective surfaces such as snow, observation sensitivity to the lower troposphere is larger and has less dependence on a priori $\mathrm{NO}_{2}$ profiles (Lorente et al., 2017; O'Byrne et al., 2010). Thus, omitting snow-covered scenes means omitting the observations with the greatest sensitivity to the lower troposphere. This could be remedied by using a product that would allow for snow cover identification to be done with confidence.

Several data products provide information on snow extent using surface station observations, satellite-observed radiances, or visible imagery. Previous evaluations have found it difficult to determine which of these products is definitively the best, partly due to differences in resolution. Most products are more consistent during the winter months when persistent, deep snow is present (Frei et al., 2012; Frei and Lee, 2010). However, disagreements are common during accumulation and melting seasons, over mountains, and under forest canopies. These evaluations have largely focused on local or regional snow cover or have included only cloud-free observations.

The upcoming geostationary Tropospheric Emissions: Monitoring of Pollution (TEMPO) satellite instrument will provide hourly observations of air quality relevant trace gases over North America at an unprecedented spatial and temporal resolution (Zoogman et al., 2017). As is the case for all nadir satellite retrievals, the quality of these observations will depend on the accuracy of the surface reflectance used in the retrieval. As a significant portion of the observed domain experiences snow cover, an accurate representation of snow cover is needed. Current plans to deal with snow cover for TEMPO are to rely on external observations.

In this work, we examine the importance of accurate snow identification by using a radiative transport model to evaluate how the vertical sensitivity of a satellite retrieval is impacted by surface reflectance. We then assess seven snow extent products that are expected to continue to be operational during the TEMPO mission using in situ observations across North America with the intent of determining which product is best suited for providing snow cover information for TEMPO and other future satellite retrievals. Finally, we combine radiative transfer model results with a snow extent product to show how including snow-covered scenes improves both the quantity and quality of information in a retrieval data set.

\section{Data and algorithms}

\subsection{Gridded snow products}

\subsubsection{IMS}

One of the most widely used sources of snow extent data is the Interactive Multisensor Snow and Ice Mapping System (IMS). IMS provides daily, near-real-time maps of snow and sea ice cover in the Northern Hemisphere at $4 \mathrm{~km}$ resolution (Helfrich et al., 2007). The maps are produced by a trained analyst using visible imagery from a collection of geostationary (e.g. GOES, MeteoSat) and polar orbiting (e.g. AVHRR, MODIS, SAR) satellite instruments, with additional information from microwave sensors (e.g. DMSP, AMSR, AMSU), surface observations (e.g. SNOTEL), and models (e.g. SNODAS) (Helfrich et al., 2007). By using multiple sources of information with different spatial resolution and temporal sampling, IMS can minimize interference from clouds.

\subsubsection{MODIS}

A second commonly used snow and ice product is derived from MODIS satellite observations from the Terra and Aqua satellites (Hall and Riggs, 2007). Terra and Aqua have sunsynchronous, near-polar orbits with overpass times of 10:30 and 13:30, respectively. Snow cover is calculated using a Normalized Difference Snow Index (NDSI), which examines the difference between observed radiation at visible wavelengths (where snow is highly reflective) and short infrared wavelengths (where there is little reflection from snow). Observations are made at $500 \mathrm{~m}$ spatial resolution and aggregated to produce daily snow cover fractions on a $0.05^{\circ}$ resolution grid. Past evaluations of the standard MODIS snow 
product show good agreement in cloud-free conditions but often snow is misidentified as cloud (Hall and Riggs, 2007; Yang et al., 2015).

The Multiangle Implementation of Atmospheric Correction (MAIAC) algorithm is another algorithm processing MODIS observations. MAIAC retrievals uses radiances observed by the MODIS Aqua and Terra satellites to provide atmospheric and surface products including snow detection on a $1 \mathrm{~km}$ grid (Lyapustin et al., 2011a, b, 2012). While the NDSI used by the standard MODIS product is also used by MAIAC as one of the criteria, the overall snow and cloud detection in MAIAC are different from the standard MODIS algorithm (Lyapustin et al., 2008).

\subsubsection{NISE}

The Near-real-time Ice and Snow Extent (NISE) provides daily updated snow cover extent information on a $25 \times 25 \mathrm{~km}$ grid (Nolin et al., 2005). NISE uses microwave measurements from the Special Sensor Microwave Imager/Sounder (SSM/I) on a sun-synchronous, quasi-polar orbit to observe how microwave radiation emitted by soil is scattered by snow. Products based on microwave measurements such as NISE are known to miss wet and thin snow, as wet snow emits microwave radiation similar to soil, and thin snow does not provide sufficient scattering.

\subsubsection{CMC}

The Canadian Meteorological Centre (CMC) Daily Snow Depth Analysis Data is a statistical interpolation of snow depth measurements from 8000 surface sites across Canada and US interpolated using a snow pack model (Brasnett, 1999). Unlike the aforementioned satellite products that provide snow extent, CMC provides snow depths. Daily snow maps are produced at $25 \mathrm{~km}$ resolution. As it a reanalysis product, there is a time delay in availability. The CMC snow depths show good agreement with independent observations over midlatitudes and is considered an improvement over previous snow depth climatologies (Brown et al., 2003).

\subsection{Surface observations}

These snow identification products are evaluated against surface station observations from the Global Historical Climatology Network Daily (GHCN-D) database, an amalgamation of daily climate records from over 80000 surface stations worldwide (Menne et al., 2012a). Most observations over Canada and the United States are collected by government organizations (Environment and Climate Change Canada and NOAA National Climatic Data Center, respectively) with additional measurements from smaller observation networks. While the focus of the database is collecting temperature and precipitation measurements, many stations (1279 in Canada and 13932 in the United States in 2015 used here) also offer snow depth measurements.
A subset of the surface stations included in GHCN-D may also be used in the CMC reanalysis. It is difficult to definitively know which stations are used, as CMC does not routinely archive this information. However, we estimate that only $5 \%$ of the GHCN-D stations used here are located within $0.1^{\circ}$ of a possible CMC station, and thus GHCN-D has sufficient independent information sources to evaluate the CMC product.

\subsection{Radiative transfer calculations}

The sensitivity of satellite observations of $\mathrm{NO}_{2}$ to its vertical distribution is calculated here using the LIDORT radiative transfer model (Spurr, 2002). The model is used to calculate scattering weights, which quantify the sensitivity of backscattered solar radiation to $\mathrm{NO}_{2}$ at different altitudes (Martin et al., 2002; Palmer et al., 2001). The observation sensitivity to lower tropospheric $\mathrm{NO}_{2}$ is represented by the AMF. AMFs for OMI satellite observations in January 2013 are calculated as a useful analog for future TEMPO observations as both instruments are spectrometers observing reflected sunlight at UV to visible wavelengths. AMFs are calculated at $440 \mathrm{~nm}$, at the centre of the $\mathrm{NO}_{2}$ retrieval window for OMI and TEMPO where $\mathrm{NO}_{2}$ has strong absorption features. Vertical $\mathrm{NO}_{2}$ profiles, as well as other trace gas and aerosol profiles needed for the AMF calculation shown here, are obtained from a simulation of the GEOS-Chem chemical transport model version 11-01 (www.geos-chem.org).

Figure 1 shows maps of snow-free and snow-covered reflectances used here. Snow-free surface reflectance at $470 \mathrm{~nm}$ is provided by Nadir BRDF-Adjusted Reflectances from the MODIS CMG Gap-Filled Snow-Free Products (Sun et al., 2017). Reflectivities at $354 \mathrm{~nm}$ for snow-covered scenes are derived from OMI observations as described by O'Byrne et al. (2010). This data set is consistent with previous snow reflectivity (e.g. Moody et al., 2007; Tanskanen and Manninen, 2007) over most land types (O’Byrne et al., 2010). Snow-covered reflectivity has an estimated uncertainty of $10-20 \%$ in most regions, with higher uncertainties in regions with thin or transient snow. Although the $354 \mathrm{~nm}$ wavelength is different than the $440 \mathrm{~nm}$ wavelength used to calculate AMFs, snow reflectivity has weak spectral dependence in UV-visible wavelengths (Feister and Grewe, 1995; O'Byrne et al., 2010). Snow can increase surface reflectance by over a factor of 10 in central North America where short vegetation is readily covered by snow.

\section{Methods}

Here we test daily snow cover products for 2015. Snow products are regridded from their native resolutions to a common $4 \mathrm{~km}$ grid (similar to the spatial resolution of TEMPO). A grid box is considered to be snow covered if any observations within that box are snow covered. MAIAC, NISE, and IMS 
(a) Snow-covered reflectance

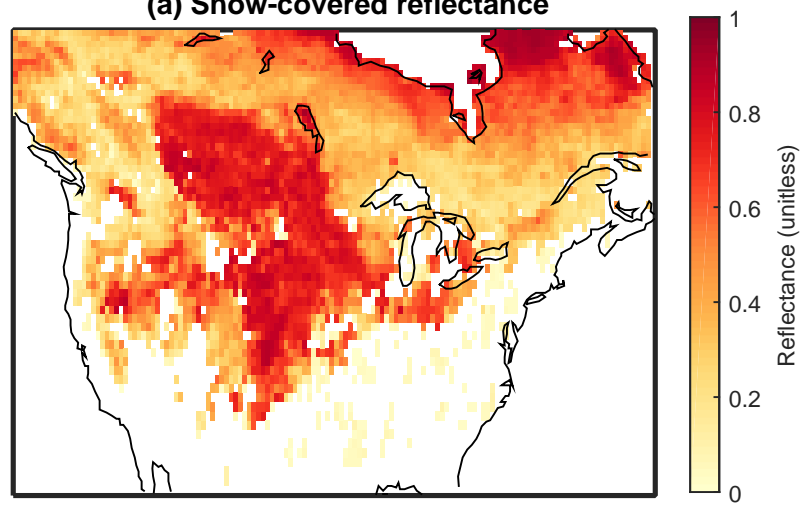

(b) Snow-free reflectance

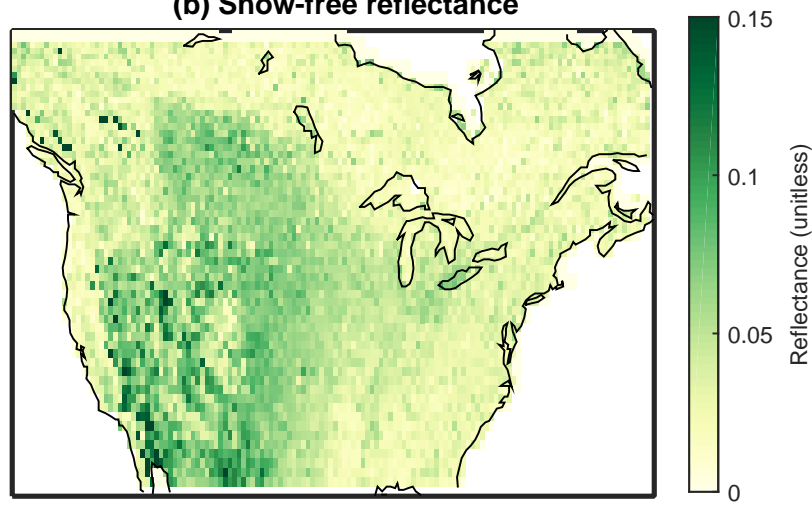

Figure 1. Surface reflectivity at UV-visible wavelengths for snowcovered and snow-free conditions for January 2013. White space in panel (a) indicates that no snow reflectance information is available.

give only a yes or no flag for presence of snow. MODIS products provide a pixel snow fraction, and we consider any pixels with nonzero snow fractions as snow covered. Any CMC grid box with nonzero snow depth is considered snow covered.

GHCN-D surface measurements are used as the ground "truth" for evaluating the satellite and reanalysis snow data products tested here. If measurements from multiple surface data networks exist in the same grid box, the most reliable source is used per the priority order given by GHCN-D (Menne et al., 2012b). If observations from multiple surface stations within the most reliable network within a grid box disagree on the presence of snow on a given day, that day is excluded from the evaluation.

We assess the snow data sets using metrics that are commonly used for evaluating binary data sets (Rittger et al., 2013). These metrics are based on the possible outcomes for identifying snow: true positive (TP), true negative (TN), false positive (FP), and false negative (FN). Accuracy measures the likelihood that a grid box, with snow or without, is correctly classified:

Accuracy $=\frac{\mathrm{TP}+\mathrm{TN}}{\mathrm{TP}+\mathrm{TN}+\mathrm{FP}+\mathrm{FN}}$.
Precision is the probability that a region identified as snow covered has snow:

Precision $=\frac{\mathrm{TP}}{\mathrm{TP}+\mathrm{FP}}$.

Recall is the likelihood that snow cover is detected when present:

Recall $=\frac{\mathrm{TP}}{\mathrm{TP}+\mathrm{FN}}$.

The $F$ score balances recall (which accounts for false negatives) and precision (which accounts for false positives) to measure correct classification of snow without the influence of frequent snow-free periods, and it is therefore the metric which is most relevant for TEMPO:

$F=2 \cdot \frac{\text { precision } \cdot \text { recall }}{\text { precision }+ \text { recall }}$.

\section{Results}

We first examine the effect of surface reflectivity on retrieval sensitivity by using the LIDORT radiative transfer model to calculate $\mathrm{NO}_{2}$ AMFs for both snow-free and snowcovered scenarios using the corresponding snow-free (Sun et al., 2017) or snow-covered (O'Byrne et al., 2010) surface reflectance over North America. We calculate AMFs over North America in January 2013. We assume cloud-free conditions in all AMF calculations, as the impact of surface reflectance on retrieved cloud fractions is beyond the scope of this paper.

Figure 2 shows the sensitivity of backscattered radiation (scattering weights) over snow-covered and snow-free surfaces for two locations: a midlatitude location (US Midwest; $42^{\circ} \mathrm{N}, 99^{\circ} \mathrm{W}$ ) with a solar zenith angle of $60^{\circ}$ and at a highlatitude location (Northern Canada; $58^{\circ} \mathrm{N}, 76^{\circ} \mathrm{W}$ ) with a solar zenith angle of $79^{\circ}$. The snow-covered scattering weights are greater than the snow-free scattering weights throughout the troposphere, by factors of 2.0 (2.7) below $5 \mathrm{~km}, 2.7$ (3.7) below $2 \mathrm{~km}$, and 2.6 (5.3) below $1 \mathrm{~km}$ at the mid- (high-) latitude location. This shows that satellite-observed backscattered radiation in clear-sky conditions is up to 5 times as sensitive to $\mathrm{NO}_{2}$ in the boundary layer after accounting for increased reflection by snow, due to the increased absorption by $\mathrm{NO}_{2}$ in the lower troposphere when the surface reflects more sunlight.

Figure 3 shows the distribution of AMF values over North America with and without reflectance from snow. The snowfree AMF distribution is unimodal with a median of 1.2. Allowing for the presence of snow introduces a second mode with a median of 3.2. Mean AMFs increase by a factor of 2.0 in the presence of snow, indicating an overall doubling in the sensitivity to tropospheric $\mathrm{NO}_{2}$ over snow-covered surfaces across North America. The impact is larger over polluted regions, as mean AMFs increase by a factor of 2.2 in 

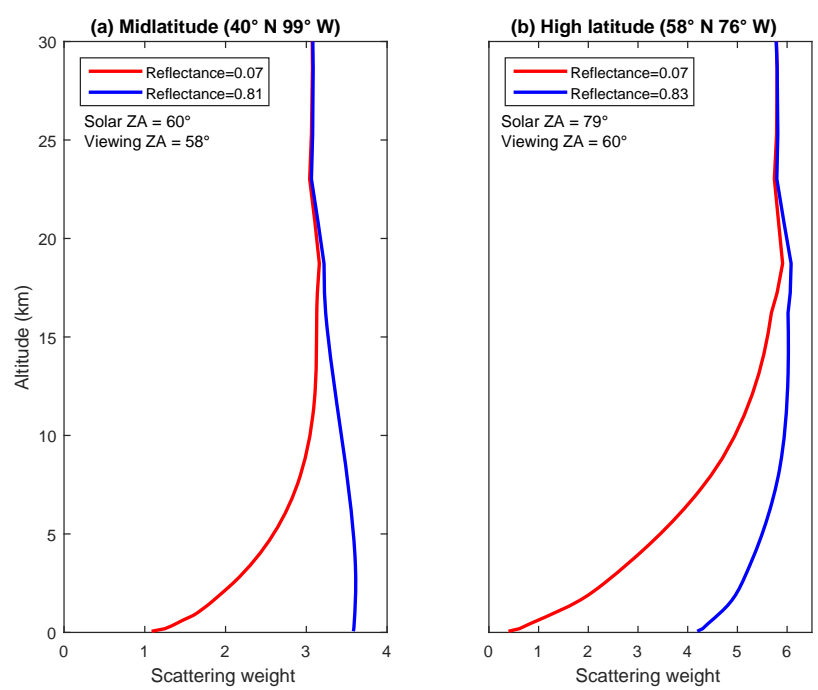

Figure 2. Observation sensitivity to $\mathrm{NO}_{2}$. Scattering weight profiles calculated for cloud-free $\mathrm{OMI} \mathrm{NO}_{2}$ retrievals, with and without surface snow cover, for January 2013 at (a) $42^{\circ} \mathrm{N}, 99^{\circ} \mathrm{W}$ with a solar zenith angle (ZA) of $60^{\circ}$ and (b) $58^{\circ} \mathrm{N}, 76^{\circ} \mathrm{W}$ with a solar zenith angle of $79^{\circ}$.

regions where $\mathrm{NO}_{2}$ columns exceed $1 \times 10^{15}$ molec $\mathrm{cm}^{-2}$. Maps of AMF with and without snow cover for January 2013 show that AMF values increase over $69 \%$ of the land surface within the TEMPO domain.

We next examine the snow datasets to identify the one most suited for the TEMPO retrieval algorithm. Figure 4 shows the spatial distribution of false positives and false negatives in the data sets. In all data sets, both false positives and negatives are most frequent over mountainous regions, particularly in the Rocky Mountain region, consistent with previous validation studies (Chen et al., 2012, 2014; Frei et al., 2012; Frei and Lee, 2010). These errors are often attributed to differences in representativeness, as snow cover in mountain regions is often spatially inhomogeneous, and thus in situ measurements may not be representative of the pixel. A slight increase in the number of false positives in IMS over mid-western and prairie regions may result from crop regions with high snow-free albedos being mistaken for snow in visible imagery (Chen et al., 2012; Yang et al., 2015). NISE, MODIS Aqua, and MODIS Terra have more false negatives overall, especially in the Great Lakes and New England regions. False positives are less frequent than false negatives in all data sets. IMS and CMC have the lowest frequency of false negatives. NISE and MAIAC have the lowest frequency of false positives.

Figure 5 shows the metrics used to evaluate data set performance. Table 1 summarizes these results. All data sets have high accuracy numbers, owing largely to a high number of true negatives during the summer months. MODIS Aqua and Terra have low recall and $F$ scores. When only observa-

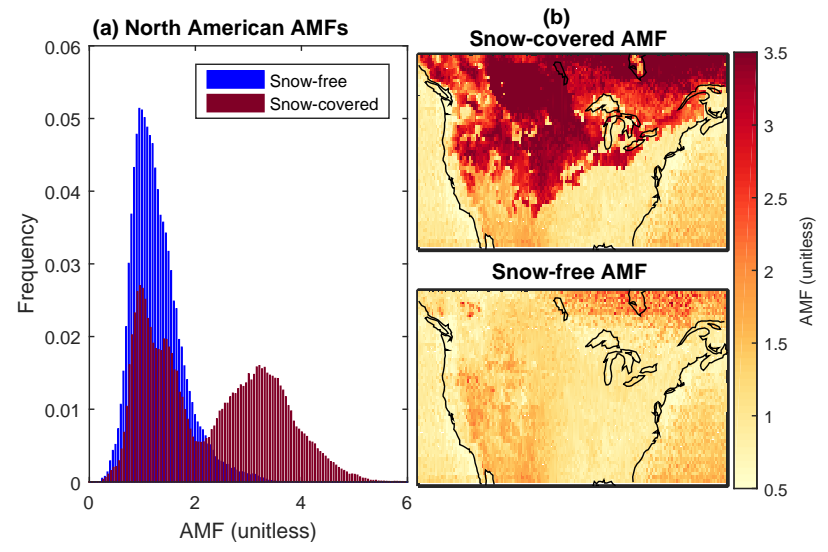

Figure 3. (a) Distribution of air mass factors (AMFs) calculated for $\mathrm{OMI} \mathrm{NO} 2$ retrievals over North America for observation geometry of January 2013, using snow-free (Sun et al., 2017) or snow-covered (O'Byrne et al., 2010) surface reflectance. (b) Maps of AMF for snow-covered and snow-free conditions.

tions with MODIS cloud fractions less than $20 \%$ are used, MODIS has better agreement with the ground stations ( $F$ statistic increases from 0.38 to 0.49 at native resolution for Aqua, 0.43 to 0.63 for Terra), but this reduces the number of usable MODIS observations by up to $60 \%$. NISE has high precision but low recall, indicating that, while areas classified as snow-covered by NISE are likely correct, many snowcovered regions are missing in the data set. This is consistent with evaluations by McLinden et al. (2014) and O'Byrne et al. (2010). Although CMC, IMS, and MAIAC products show an increase in frequency of false negatives over the Rocky Mountains, they retain a high precision in this region due to frequent snow cover. While MAIAC Aqua and Terra have high accuracy and precision, lower recall values indicate that they are conservative in identifying the presence of snow. This is possibly a consequence of the method used for identifying cloud, which may incorrectly classify fresh snowfall as cloud (Lyapustin et al., 2008). Data sets were also evaluated by season with similar results (Appendix Table A1). All data sets have weaker performance metrics during the spring melt season, which has been observed in past evaluations (Frei et al., 2012). IMS has the highest $F$ score in winter and autumn but is slightly outperformed by MAIAC in spring. Data sets were also evaluated at their native resolutions and at a common $25 \mathrm{~km}$ resolution (Appendix Tables A2-A3). Results are similar at each resolution with two exceptions: MODIS Aqua and Terra products perform better when regridded from their native $0.05^{\circ}$ resolution to a $4 \mathrm{~km}$ resolution as it reduces the number of grid boxes missing observations due to cloud, and MAIAC Aqua and Terra perform better at their native resolution than at either $4 \mathrm{~km}$ or $25 \mathrm{~km}$ as degrading the spatial resolution results in a loss of information.

For all data sets, recall is generally low in two regions: along the Pacific coastline where snow depths are relatively 

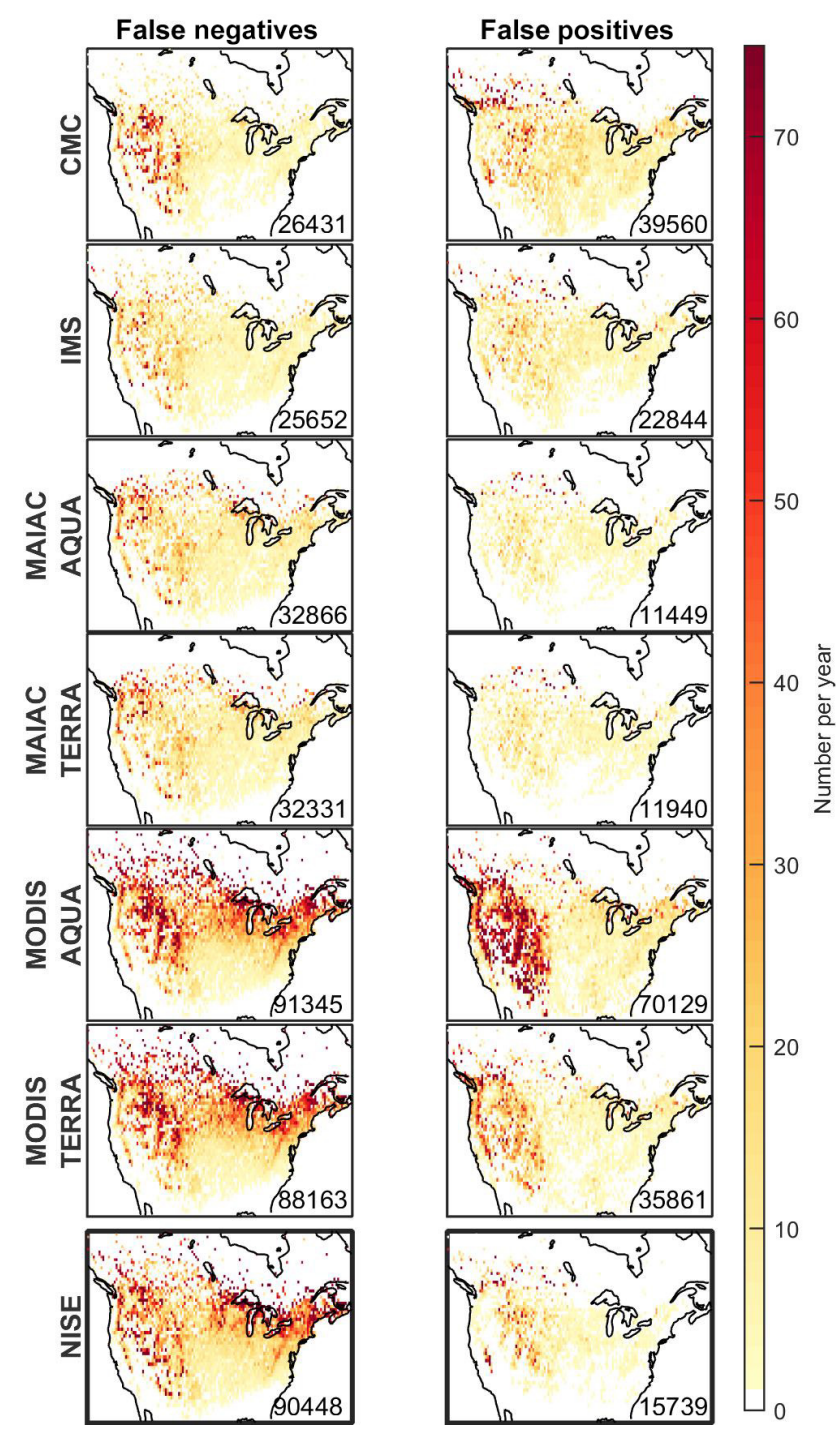

Figure 4. Number of false positive (FP) and false negative (FN) snow attributions by the snow data sets in 2015. All data sets are evaluated at $4 \mathrm{~km}$ resolution. Total number of false snow attributions inset. White space indicates that no ground stations present.

Table 1. Evaluation of daily snow extent data set performance for 2015. GHCN-D surface observations are used as "truth". All products are regridded to a common $4 \mathrm{~km}$ resolution. The highest value for each metric is shown in bold.

\begin{tabular}{lrrrr}
\hline & Accuracy & Precision & Recall & F \\
\hline CMC & 0.91 & 0.79 & $\mathbf{0 . 8 3}$ & 0.81 \\
IMS & $\mathbf{0 . 9 3}$ & 0.87 & $\mathbf{0 . 8 3}$ & $\mathbf{0 . 8 5}$ \\
MAIAC AQUA & 0.91 & $\mathbf{0 . 9 0}$ & 0.74 & 0.82 \\
MAIAC TERRA & 0.91 & $\mathbf{0 . 9 0}$ & 0.75 & 0.82 \\
MODIS AQUA & 0.76 & 0.51 & 0.43 & 0.46 \\
MODIS TERRA & 0.82 & 0.69 & 0.45 & 0.54 \\
NISE & 0.84 & 0.83 & 0.45 & 0.58 \\
\hline
\end{tabular}
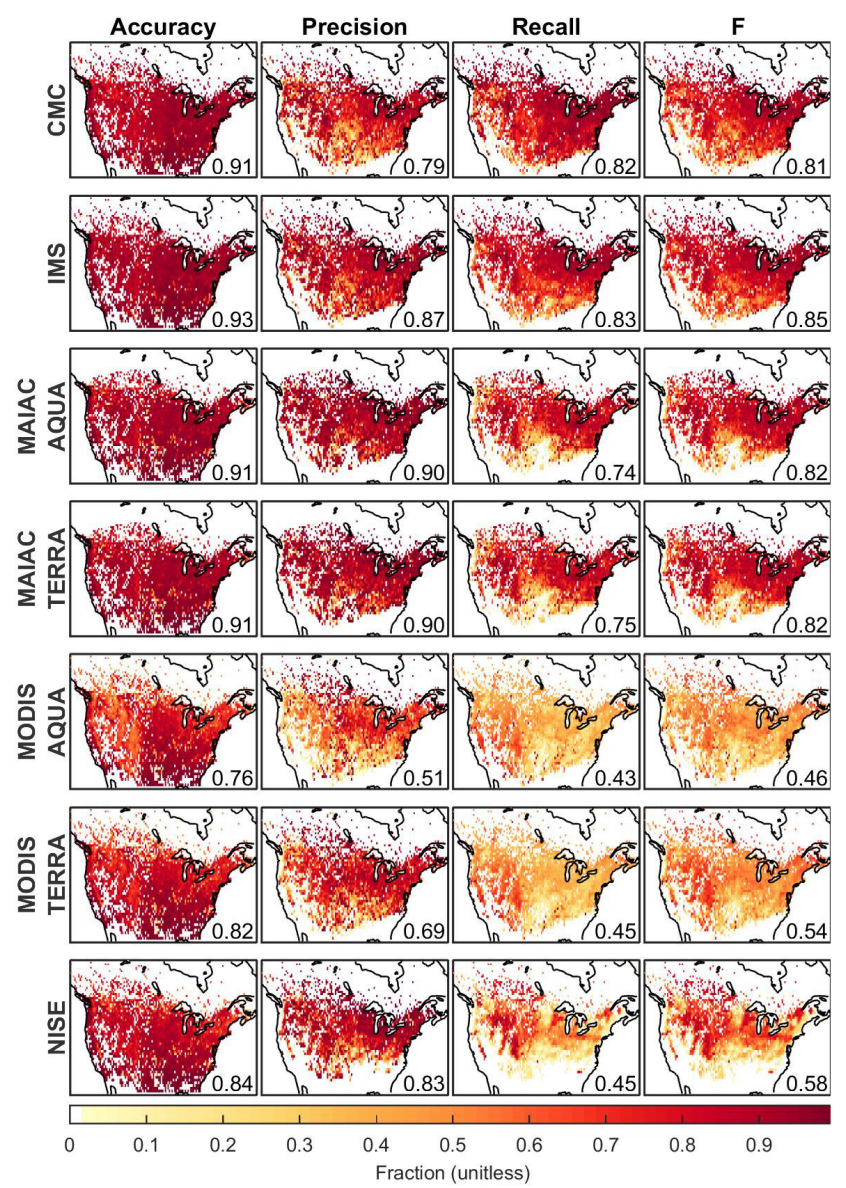

Figure 5. Statistical metrics to evaluate snow cover products. All data sets are gridded at $4 \mathrm{~km}$ resolution. White space indicates that no ground stations present.

thin and in the south when snow is rare and generally short lived. Thin snow is likely to be less homogenous across a pixel and more likely to be obscured by forest canopies or tall grasses, and thus it is difficult to observe from satellite imagery. Short-lived snow in the south is likely to be missed by satellite observations, especially since clouds are often present. However, as IMS uses multiple observations at multiple times of day in addition to incorporating ground station data, it is more likely to find snow in these cases than other satellite products (Hall et al., 2010). Overall, IMS has best agreement with in situ observations, with the highest accuracy, recall, and $F$ statistic and relatively high precision.

While CMC also has strong performance metrics, it is important to consider the information source used to describe snow extent in each product. Products based on satellite observations are advantageous when assessing how surface reflectivity affects backscattered radiation observed from space. For example, thin snow, or snow obscured by tree canopies, may not affect the observed brightness from space, but would be considered snow-covered by a product based on surface observations (e.g. CMC). Also, the reflectivity 
of a snow-covered surface decreases over time as the snow ages (Warren and Wiscombe, 1980). This effect would not be captured by snow depth measurements. And while snow depth has been used as an indicator of brightness (Arola et al., 2003), it cannot account for snow aging or canopy effects. IMS is based on visible satellite imagery and thus determines snow extent based on brightness from space, which is more applicable to satellite retrievals. Additionally, while most satellite-based products rely on observations made at a single overpass time and viewing geometry, IMS has the advantage of incorporating observations from multiple satellites with differing measurement times and geometries, including both geostationary and low Earth orbits. These reasons, in addition to a strong agreement with in situ measurements and near-real-time updates, make IMS best suited for informing TEMPO retrievals.

We next examine the effect on both spatial sampling and sensitivity to the lower troposphere of a retrieval data set if observations with surface snow are included rather than omitted. We use IMS to identify the presence of snow for OMI observations over North America in January 2015. We then use LIDORT to calculate AMFs for these observations using the corresponding snow-free (Sun et al., 2017) or snow-covered (O'Byrne et al., 2010) surface reflectance and examine the results of either including or omitting snow-covered scenes. Figure 6 shows that including snow-covered scenes results in a significant (factor of 2.1) increase in observation frequency, particularly in the northern US and Canada. Additionally, including snow-covered scenes increases the average AMF by a factor of 2.7 in regions with occasional snow cover. The increase in AMF demonstrates that including snow-covered scenes increases the quality of information about the tropospheric $\mathrm{NO}_{2}$ column by increasing the observation sensitivity to tropospheric $\mathrm{NO}_{2}$. As we assume clear-sky conditions, these are likely upper bounds on potential increases in observation quantity and quality. In practice, the presence of clouds and errors in cloud retrieval algorithms will likely diminish these impacts.

\section{Conclusions}

An accurate representation of snow cover is essential to ensuring satellite retrieval accuracy, including those from TEMPO. Radiative transfer model calculations indicate that clear-sky $\mathrm{NO}_{2}$ retrievals over reflective snow-covered surfaces are more than twice as sensitive to $\mathrm{NO}_{2}$ in the boundary layer than over snow-free surfaces. This makes snow an attractive surface over which to observe tropospheric $\mathrm{NO}_{2}$. However, the lack of confidence in snow identification has previously led many retrieval procedures to omit observations over snow. We show that increasing this confidence such that these observations could be included not only improves spatial and temporal sampling but also allows the in- (a)

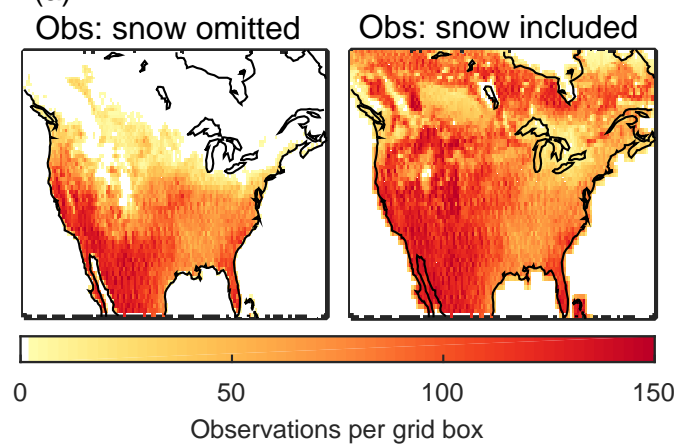

(b)

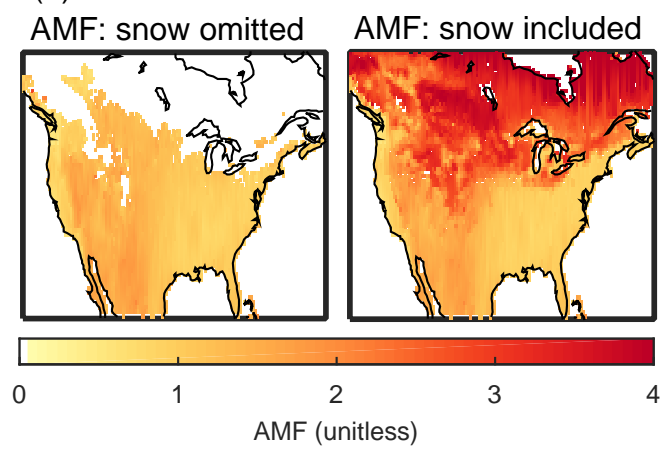

Figure 6. OMI observation frequency (a) and average AMFs (b) over North America in January using IMS to identify surface snow conditions. White space indicates a lack of observations.

clusion of observations with higher-quality information on the lower troposphere.

We evaluated seven snow extent data sets to determine their usefulness for informing satellite retrievals of trace gas from solar backscatter observations. All products were more likely to misidentify snow over mountains or where snow cover is thin or short lived. IMS had the best agreement with in situ observations $(F=0.85)$ and as a satellite-based, operational, daily updated product, it is well suited for informing TEMPO satellite retrievals. The low recall value $(0.45)$ for NISE indicated that a significant number of snow-covered pixels are missed. The standard MODIS products showed medium precision and low recall owing to cloud contamination. The MAIAC products had the highest precision $(0.90$ for both Aqua and Terra) of those tested, but is conservative in ascribing the presence of snow (recall of 0.74 for Aqua, 0.75 for Terra). CMC had strong performance metrics $(F=0.81)$, but as a reanalysis product based on ground observations it may not appropriately represent how a surface snow reflectivity would affect TEMPO-observed radiances.

The potential improvements in $\mathrm{NO}_{2}$ retrieval performance over snow-covered scenes outlined here were tested for clearsky conditions. The accuracy of cloud retrieval schemes also impacts the quality of trace gas retrievals. Many cloud retrieval schemes have difficulty distinguishing between a 
bright surface and bright, low-altitude clouds. This may diminish the impact that improved surface snow reflectance can have on observation frequency and sensitivity when clouds are present. However, using accurate surface snow cover information may also lead to corresponding improvements in cloud retrieval accuracy.

Future work should investigate snow reflectance products that could be used when snow is detected. This could potentially include bidirectional reflectance distribution functions that describe reflection at different viewing angles, as this effect has been shown to have significant impact on retrieved $\mathrm{NO}_{2}$ columns and clouds (Lorente et al., 2018; Vasilkov et al., 2017). Accurate knowledge of snow reflectivity is also needed to improve retrievals over snow. A retrieval algorithm that combines daily snow detection from IMS with a climatology of snow reflectance has the potential to greatly improve upon current methodologies.

Data availability. IMS (https://doi.org/10.7265/N52R3PMC, National Ice Center, 2008), NISE $\begin{array}{lll}\text { (https://doi.org/10.5067/3KB2JPLFPK3R, } & \\ \text { Srodzik 2016), MODIS }\end{array}$ (https://doi org/10.5067/MODIS/MYD10C1.006, MODIS Aqua Hall and Riggs, 2016a), MODIS Terra (https://doi.org/10.5067/MODIS/MOD10C1.006, Hall and Riggs, 2016b), and CMC (Brown and Brasnett, 2010) data are available from the NASA National Snow and Ice Data Center (http://nsidc.org, last access: 17 July 2017). MAIAC Collection 6 (Lyapustin et al., 2011a, b, 2012) re-processing of MODIS data started in September 2017 and is expected to be completed by the end of year. This study used MAIAC Atmospheric Properties files currently available via ftp at the NASA Center for Climate Simulations (NCCS): ftp://maiac@dataportal.nccs.nasa.gov/DataRelease/ (last access: 15 June 2017). GHCN-D data are available from the NOAA National Climatic Data Center (https://doi.org/10.7289/V5D21VHZ Menne et al., 2012b). AMF code (Spurr, 2002; Martin et al., 2002) used to calculate scattering weights and air mass factors, as well as snow-covered Surface LER (O'Byrne et al., 2010) used here, is available at http://fizz.phys.dal.ca/ atmos (last access: 19 June 2017) MODIS MCD43GF CMG Gap-Filled. Snow-free surface reflectances (Sun et al., 2017) are available at ftp://rsftp.eeos.umb.edu/data02/Gapfilled/ (Sun et al., 2017). The GEOS-Chem chemical transport model used here is available at www.geos-chem.org (last access: 15 June 2017). 


\section{Appendix A}

Table A1. Evaluation of daily snow extent data set performance by season for 2015. GHCN-D surface observations are used as "truth". All products are regridded to a common $4 \mathrm{~km}$ resolution. The highest value for each metric/season is shown in bold.

\begin{tabular}{llrrrr}
\hline Months & Data set & Accuracy & Precision & Recall & $F$ \\
\hline DJF & CMC & 0.84 & 0.84 & 0.89 & 0.86 \\
& IMS & $\mathbf{0 . 8 8}$ & 0.90 & $\mathbf{0 . 8 8}$ & $\mathbf{0 . 8 9}$ \\
& MAIAC AQUA & 0.84 & $\mathbf{0 . 9 3}$ & 0.80 & 0.86 \\
& MAIAC TERRA & 0.84 & 0.92 & 0.80 & 0.86 \\
& MODIS AQUA & 0.58 & 0.84 & 0.34 & 0.48 \\
& MODIS TERRA & 0.60 & 0.88 & 0.37 & 0.52 \\
& NISE & 0.63 & 0.90 & 0.41 & 0.57 \\
\hline \multirow{2}{*}{ MAM } & CMC & 0.90 & 0.63 & 0.57 & 0.59 \\
& IMS & $\mathbf{0 . 9 3}$ & 0.74 & $\mathbf{0 . 6 7}$ & 0.70 \\
& MAIAC AQUA & $\mathbf{0 . 9 3}$ & $\mathbf{0 . 8 1}$ & 0.62 & $\mathbf{0 . 7 1}$ \\
& MAIAC TERRA & $\mathbf{0 . 9 3}$ & $\mathbf{0 . 8 1}$ & 0.63 & $\mathbf{0 . 7 1}$ \\
& MODIS AQUA & 0.86 & 0.43 & 0.39 & 0.41 \\
& MODIS TERRA & 0.89 & 0.62 & 0.40 & 0.49 \\
& NISE & 0.90 & 0.71 & 0.34 & 0.46 \\
\hline \multirow{2}{*}{ SON } & CMC & 0.91 & 0.73 & $\mathbf{0 . 8 1}$ & 0.76 \\
& IMS & $\mathbf{0 . 9 2}$ & 0.82 & 0.74 & $\mathbf{0 . 7 8}$ \\
& MAIAC AQUA & 0.91 & $\mathbf{0 . 8 6}$ & 0.60 & 0.71 \\
& MAIAC TERRA & 0.90 & 0.85 & 0.61 & 0.71 \\
& MODIS AQUA & 0.82 & 0.51 & 0.36 & 0.42 \\
& MODIS TERRA & 0.86 & 0.71 & 0.39 & 0.51 \\
& NISE & 0.85 & 0.85 & 0.25 & 0.39 \\
\hline
\end{tabular}

Table A2. Evaluation of daily snow extent data set performance for 2015. GHCN-D surface observations are used as "truth". The highest value for each metric is shown in bold.

\begin{tabular}{lrrrrc}
\hline & Resolution & Accuracy & Precision & Recall & $F$ \\
\hline CMC & $25 \mathrm{~km}$ & 0.92 & 0.81 & 0.81 & 0.81 \\
IMS & $4 \mathrm{~km}$ & $\mathbf{0 . 9 3}$ & 0.87 & $\mathbf{0 . 8 3}$ & $\mathbf{0 . 8 5}$ \\
MAIAC AQUA & $1 \mathrm{~km}$ & 0.91 & $\mathbf{0 . 9 1}$ & 0.71 & 0.80 \\
MAIAC TERRA & $1 \mathrm{~km}$ & 0.91 & 0.90 & 0.71 & 0.80 \\
MODIS AQUA & $0.05^{\circ}$ & 0.77 & 0.50 & 0.30 & 0.37 \\
MODIS TERRA & $0.05^{\circ}$ & 0.81 & 0.65 & 0.32 & 0.43 \\
NISE & $25 \mathrm{~km}$ & 0.85 & 0.87 & 0.37 & 0.51 \\
\hline
\end{tabular}

Table A3. Evaluation of daily snow extent data set performance for 2015. GHCN-D surface observations are used as "truth". All products are regridded to a common $25 \mathrm{~km}$ resolution. The highest value for each metric is shown in bold.

\begin{tabular}{lrrrr}
\hline & Accuracy & Precision & Recall & $F$ \\
\hline CMC & 0.92 & 0.81 & 0.81 & 0.81 \\
IMS & $\mathbf{0 . 9 3}$ & 0.84 & $\mathbf{0 . 8 5}$ & $\mathbf{0 . 8 4}$ \\
MAIAC AQUA & 0.87 & 0.69 & 0.73 & 0.71 \\
MAIAC TERRA & 0.88 & 0.68 & 0.73 & 0.71 \\
MODIS AQUA & 0.78 & 0.50 & 0.41 & 0.45 \\
MODIS TERRA & 0.83 & 0.68 & 0.43 & 0.53 \\
NISE & 0.85 & $\mathbf{0 . 8 7}$ & 0.37 & 0.52 \\
\hline
\end{tabular}


Competing interests. The authors declare that they have no conflict of interest.

Edited by: Folkert Boersma

Reviewed by: two anonymous referees

\section{References}

Arola, A., Kaurola, J., Koskinen, L., Tanskanen, A., Tikkanen, T., Taalas, P., Herman, J. R., Krotkov, N., and Fioletov, V.: A new approach to estimating the albedo for snow-covered surfaces in the satellite UV method, J. Geophys. Res., 108, 4531, https://doi.org/10.1029/2003JD003492, 2003.

Beirle, S., Boersma, K. F., Platt, U., Lawrence, M. G., and Wagner, T.: Megacity emissions and lifetimes of nitrogen oxides probed from space, Science, 333, 1737-1739, https://doi.org/10.1126/science.1207824, 2011.

Boersma, K. F., Eskes, H. J., and Brinksma, E. J.: Error analysis for tropospheric $\mathrm{NO}_{2}$ retrieval from space, J. Geophys. Res.-Atmos., 109, D04311, https://doi.org/10.1029/2003JD003962, 2004.

Brasnett, B.: A Global Analysis of Snow Depth for Numerical Weather Prediction, J. Appl. Meteorol., $\quad 38, \quad 726-740, \quad$ https://doi.org/10.1175/15200450(1999)038<0726:AGAOSD>2.0.CO;2, 1999.

Brodzik, M. J. and Stewart, J. S.: Near-Real-Time SSM/I-SSMIS EASE-Grid Daily Global Ice Concentration and Snow Extent, Version 5, https://doi.org/10.5067/3KB2JPLFPK3R, 2016.

Brown, R. D. and Brasnett, B.: Canadian Meteorological Centre (CMC) Daily Snow Depth Analysis Data, Version 1, https://doi.org/10.5067/W9FOYWH0EQZ3, 2010.

Brown, R. D., Brasnett, B., and Robinson, D.: Gridded North American monthly snow depth and snow water equivalent for GCM evaluation, Atmos.-Ocean, 41, 1-14, https://doi.org/10.3137/ao.410101, 2003.

Chen, C., Lakhankar, T., Romanov, P., Helfrich, S., Powell, A., and Khanbilvardi, R.: Validation of NOAA-Interactive Multisensor Snow and Ice Mapping System (IMS) by Comparison with Ground-Based Measurements over Continental United States, Remote Sens., 4, 1134-1145, https://doi.org/10.3390/rs4051134, 2012.

Chen, X., Jiang, L., Yang, J., and Pan, J.: Validation of ice mapping system snow cover over southern China based on Landsat Enhanced Thematic Mapper Plus imagery, J. Appl. Remote Sens., 8, 84680, https://doi.org/10.1117/1.JRS.8.084680, 2014.

Duncan, B. N., Prados, A. I., Lamsal, L. N., Liu, Y., Streets, D. G., Gupta, P., Hilsenrath, E., Kahn, R. A., Nielsen, J. E., Beyersdorf, A. J., Burton, S. P., Fiore, A. M., Fishman, J., Henze, D. K., Hostetler, C. A., Krotkov, N. A., Lee, P., Lin, M., Pawson, S., Pfister, G., Pickering, K. E., Pierce, R. B., Yoshida, Y., and Ziemba, L. D.: Satellite data of atmospheric pollution for U.S. air quality applications: Examples of applications, summary of data end-user resources, answers to FAQs, and common mistakes to avoid, Atmos. Environ., 94, 647-662, https://doi.org/10.1016/j.atmosenv.2014.05.061, 2014.

Feister, U. and Grewe, R.: Spectral albedo measurements in the UV and visible region over different types of surfaces, Photochem. Photobiol., 62, 736-744, https://doi.org/10.1111/j.17511097.1995.tb08723.x, 1995.
Fioletov, V. E., McLinden, C. A., Krotkov, N., and Li, C.: Lifetimes and emissions of $\mathrm{SO}_{2}$ from point sources estimated from OMI, Geophys. Res. Lett., 42, 1969-1976, https://doi.org/10.1002/2015GL063148, 2015.

Fishman, J., Al-Saadi, J. A., Creilson, J. K., Bowman, K. W., Burrows, J. P., Richter, A., Chance, K. V., Edwards, D. P., Martin, R. V., Morris, G. A., Pierce, R. B., Ziemke, J. R., Schaack, T. K., Thompson, A. M., Fishman, J., Al-Saadi, J. A., Creilson, J. K., Bowman, K. W., Burrows, J. P., Richter, A., Chance, K. V., Edwards, D. P., Martin, R. V., Morris, G. A., Pierce, R. B., Ziemke, J. R., Schaack, T. K., and Thompson, A. M.: Remote Sensing of Tropospheric Pollution from Space, B. Am. Meteorol. Soc., 89, 805-821, https://doi.org/10.1175/2008BAMS2526.1, 2008.

de Foy, B., Lu, Z., Streets, D. G., Lamsal, L. N., and Duncan, B. N.: Estimates of power plant NO $x$ emissions and lifetimes from OMI NO 2 satellite retrievals, Atmos. Environ., 116, 1-11, 2015.

Frei, A. and Lee, S.: A comparison of optical-band based snow extent products during spring over North America, Remote Sens. Environ., 114, 1940-1948, https://doi.org/10.1016/j.rse.2010.03.015, 2010.

Frei, A., Tedesco, M., Lee, S., Foster, J., Hall, D. K., Kelly, R., and Robinson, D. A.: A review of global satellitederived snow products, Adv. Space Res., 50, 1007-1029, https://doi.org/10.1016/j.asr.2011.12.021, 2012.

Geddes, J. A. and Martin, R. V.: Global deposition of total reactive nitrogen oxides from 1996 to 2014 constrained with satellite observations of $\mathrm{NO}_{2}$ columns, Atmos. Chem. Phys., 17, 1007110091, https://doi.org/10.5194/acp-17-10071-2017, 2017.

Hall, D. K. and Riggs, G. A.: Accuracy assessment of the MODIS snow products, Hydrol. Process., 21, 1534-1547, https://doi.org/10.1002/hyp.6715, 2007.

Hall, D. and Riggs, G. A.: MODIS/Aqua Snow Cover Daily L3 Global 0.05Deg CMG, Version 6, https://doi.org/10.5067/MODIS/MYD10C1.006, 2016a.

Hall, D. K. and Riggs, G. A.: MODIS/Terra Snow Cover Daily L3 Global 0.05Deg CMG, Version 6, https://doi.org/10.5067/MODIS/MOD10C1.006, 2016b.

Hall, D. K., Fuhrmann, C. M., Perry, L. B., Riggs, G. A., Robinson, D. A., and Foster, J. L.: A Comparison of Satellite-Derived Snow Maps with a Focus on Ephemeral Snow in North Carolina, 67th Eastern Snow Conference, Hancock MA USA, 2010.

Helfrich, S. R., McNamara, D., Ramsay, B. H., Baldwin, T., and Kasheta, T.: Enhancements to, and forthcoming developments in the Interactive Multisensor Snow and Ice Mapping System (IMS), Hydrol. Process., 21, 1576-1586, https://doi.org/10.1002/hyp.6720, 2007.

Herman, J. R. and Celarier, E. A.: Earth surface reflectivity climatology at 340-380 nm from TOMS data, J. Geophys. Res.Atmos., 102, 28003-28011, https://doi.org/10.1029/97JD02074, 1997.

Kleipool, Q. L., Dobber, M. R., de Haan, J. F., and Levelt, P. F.: Earth surface reflectance climatology from 3 years of OMI data, J. Geophys. Res., 113, D18308, https://doi.org/10.1029/2008JD010290, 2008.

Koelemeijer, R. B. A., de Haan, J. F., and Stammes, P.: A database of spectral surface reflectivity in the range $335-772 \mathrm{~nm}$ derived from 5.5 years of GOME observations, J. Geophys. Res., 108, 4070, https://doi.org/10.1029/2002JD002429, 2003. 
Lamsal, L. N., Janz, S. J., Krotkov, N. A., Pickering, K. E., Spurr, R. J. D., Kowalewski, M. G., Loughner, C. P., Crawford, J. H., Swartz, W. H., and Herman, J. R.: High-resolution $\mathrm{NO}_{2}$ observations from the Airborne Compact Atmospheric Mapper: Retrieval and validation, J. Geophys. Res.-Atmos., 122, 1953-1970, https://doi.org/10.1002/2016JD025483, 2017.

Liang, S., Fang, H., Chen, M., Shuey, C. J., Walthall, C., Daughtry, C., Morisette, J., Schaaf, C., and Strahler, A.: Validating MODIS land surface reflectance and albedo products: methods and preliminary results, Remote Sens. Environ., 83, 149-162, https://doi.org/10.1016/S0034-4257(02)00092-5, 2002.

Lin, J.-T., Liu, M.-Y., Xin, J.-Y., Boersma, K. F., Spurr, R., Martin, R., and Zhang, Q.: Influence of aerosols and surface reflectance on satellite $\mathrm{NO}_{2}$ retrieval: seasonal and spatial characteristics and implications for $\mathrm{NO}_{x}$ emission constraints, Atmos. Chem. Phys., 15, 11217-11241, https://doi.org/10.5194/acp-15-112172015, 2015.

Lorente, A., Folkert Boersma, K., Yu, H., Dörner, S., Hilboll, A., Richter, A., Liu, M., Lamsal, L. N., Barkley, M., De Smedt, I., Van Roozendael, M., Wang, Y., Wagner, T., Beirle, S., Lin, J.T., Krotkov, N., Stammes, P., Wang, P., Eskes, H. J., and Krol, M.: Structural uncertainty in air mass factor calculation for $\mathrm{NO}_{2}$ and $\mathrm{HCHO}$ satellite retrievals, Atmos. Meas. Tech., 10, 759-782, https://doi.org/10.5194/amt-10-759-2017, 2017.

Lorente, A., Boersma, K. F., Stammes, P., Tilstra, L. G., Richter, A., Yu, H., Kharbouche, S., and Muller, J.-P.: The importance of surface reflectance anisotropy for cloud and $\mathrm{NO}_{2}$ retrievals from GOME-2 and OMI, Atmos. Meas. Tech. Discuss., https://doi.org/10.5194/amt-2018-32, in review, 2018.

Lyapustin, A., Wang, Y., and Frey, R.: An automatic cloud mask algorithm based on time series of MODIS measurements, J. Geophys. Res., 113, D16207, https://doi.org/10.1029/2007JD009641, 2008.

Lyapustin, A., Martonchik, J., Wang, Y., Laszlo, I., and Korkin, S.: Multiangle implementation of atmospheric correction (MAIAC): 1. Radiative transfer basis and look-up tables, J. Geophys. Res., 116, D03210, https://doi.org/10.1029/2010JD014985, $2011 \mathrm{a}$.

Lyapustin, A., Wang, Y., Laszlo, I., Kahn, R., Korkin, S., Remer, L., Levy, R., and Reid, J. S.: Multiangle implementation of atmospheric correction (MAIAC): 2. Aerosol algorithm, J. Geophys. Res., 116, D03211, https://doi.org/10.1029/2010JD014986, $2011 b$.

Lyapustin, A. I., Wang, Y., Laszlo, I., Hilker, T., G.Hall, F., Sellers, P. J., Tucker, C. J., and Korkin, S. V.: Multi-angle implementation of atmospheric correction for MODIS (MAIAC): 3. Atmospheric correction, Remote Sens. Environ., 127, 385-393, https://doi.org/10.1016/j.rse.2012.09.002, 2012.

Martin, R. V.: Satellite remote sensing of surface air quality, Atmos. Environ., 42, 7823-7843, https://doi.org/10.1016/j.atmosenv.2008.07.018, 2008.

Martin, R. V, Chance, K., Jacob, D. J., Kurosu, T. P., Spurr, R. J. D., Bucsela, E., Gleason, J. F., Palmer, P. I., Bey, I., and Fiore, A. M.: An improved retrieval of tropospheric nitrogen dioxide from GOME, J. Geophys. Res.-Atmos., 107, 4437, https://doi.org/10.1029/2001JD001027, 2002.

McLinden, C. A., Fioletov, V., Boersma, K. F., Kharol, S. K., Krotkov, N., Lamsal, L., Makar, P. A., Martin, R. V., Veefkind, J. P., and Yang, K.: Improved satellite retrievals of $\mathrm{NO}_{2}$ and $\mathrm{SO}_{2}$ over the Canadian oil sands and comparisons with surface measurements, Atmos. Chem. Phys., 14, 3637-3656, https://doi.org/10.5194/acp-14-3637-2014, 2014.

Menne, M. J., Durre, I., Vose, R. S., Gleason, B. E., Houston, T. G., Menne, M. J., Durre, I., Vose, R. S., Gleason, B. E., and Houston, T. G.: An Overview of the Global Historical Climatology Network-Daily Database, J. Atmos. Ocean. Technol., 29, 897910, https://doi.org/10.1175/JTECH-D-11-00103.1, 2012a.

Menne, M. J., Durre, I., Korzeniewski, B., McNeal, S., Thomas, K., Yin, X., Anthony, S., Ray, R., Vose, R. S., Gleason, B. E., and Houston, T. G.: Global Historical Climatology Network - Daily (GHCN-Daily), Version 3.22, https://doi.org/10.7289/V5D21VHZ, 2012b.

Moody, E. G., King, M. D., Schaaf, C. B., Hall, D. K., and Platnick, S.: Northern Hemisphere five-year average (2000-2004) spectral albedos of surfaces in the presence of snow: Statistics computed from Terra MODIS land products, Remote Sens. Environ., 111, 337-345, https://doi.org/10.1016/j.rse.2007.03.026, 2007.

National Ice Center: IMS Daily Northern Hemisphere Snow and Ice Analysis at $1 \mathrm{~km}, 4 \mathrm{~km}$, and $24 \mathrm{~km}$ Resolutions, Version 1, https://doi.org/10.7265/N52R3PMC, 2008.

Nolin, A., Armstrong, R., and Maslanik, J.: Near real-time SSM/I EASE-grid daily global ice concentration and snow extent, Digit. Media, Natl. Snow Ice Data Center, Boulder, CO, USA, 2005.

Nowlan, C. R., Martin, R. V., Philip, S., Lamsal, L. N., Krotkov, N. A., Marais, E. A., Wang, S., and Zhang, Q.: Global dry deposition of nitrogen dioxide and sulfur dioxide inferred from spacebased measurements, Global Biogeochem. Cy., 28, 1025-1043, https://doi.org/10.1002/2014GB004805, 2014.

O'Byrne, G., Martin, R. V., van Donkelaar, A., Joiner, J., and Celarier, E. A.: Surface reflectivity from the Ozone Monitoring Instrument using the Moderate Resolution Imaging Spectroradiometer to eliminate clouds: Effects of snow on ultraviolet and visible trace gas retrievals, J. Geophys. Res., 115, D17305, https://doi.org/10.1029/2009JD013079, 2010.

Palmer, P. I., Jacob, D. J., Chance, K., and Martin, R. V.: Air mass factor formulation for spectroscopic measurements from satellites' Application to formaldehyde retrievals from the Global Ozone Monitoring Experiment, J. Geophys. Res., 106, 1453914550, https://doi.org/10.1029/2000JD900772, 2001.

Richter, A. and Wagner, T.: The Use of UV, Visible and Near IR Solar Back Scattered Radiation to Determine Trace Gases, 67121, Springer, Berlin, Heidelberg, 2011.

Rittger, K., Painter, T. H., and Dozier, J.: Assessment of methods for mapping snow cover from MODIS, Adv. Water Resour., 51, 367380, https://doi.org/10.1016/j.advwatres.2012.03.002, 2013.

Spurr, R. J. D.: Simultaneous derivation of intensities and weighting functions in a general pseudo-spherical discrete ordinate radiative transfer treatment, J. Quant. Spectrosc. Ra., 75, 129-175, 2002.

Streets, D. G., Canty, T., Carmichael, G. R., de Foy, B., Dickerson, R. R., Duncan, B. N., Edwards, D. P., Haynes, J. A., Henze, D. K., and Houyoux, M. R.: Emissions estimation from satellite retrievals: A review of current capability, Atmos. Environ., 77, 1011-1042, 2013.

Sun, Q., Wang, Z., Li, Z., Erb, A., and Schaaf, C. B.: Evaluation of the global MODIS 30 arc-second spatially and temporally complete snow-free land surface albedo and reflectance anisotropy dataset, Int. J. Appl. Earth Obs. Geoinf., 58, 36-49, https://doi.org/10.1016/j.jag.2017.01.011, 2017. 
Tanskanen, A. and Manninen, T.: Effective UV surface albedo of seasonally snow-covered lands, Atmos. Chem. Phys., 7, 27592764, https://doi.org/10.5194/acp-7-2759-2007, 2007.

Valin, L. C., Russell, A. R., and Cohen, R. C.: Variations of OH radical in an urban plume inferred from $\mathrm{NO}_{2}$ column measurements, Geophys. Res. Lett., 40, 1856-1860, 2013.

Vasilkov, A., Qin, W., Krotkov, N., Lamsal, L., Spurr, R., Haffner, D., Joiner, J., Yang, E.-S., and Marchenko, S.: Accounting for the effects of surface BRDF on satellite cloud and trace-gas retrievals: a new approach based on geometry-dependent Lambertian equivalent reflectivity applied to OMI algorithms, Atmos. Meas. Tech., 10, 333-349, https://doi.org/10.5194/amt-10-3332017, 2017.

Warren, S. G. and Wiscombe, W. J.: A Model for the Spectral Albedo of Snow. II: Snow Containing Atmospheric Aerosols, J. Atmos. Sci., 37, 2734-2745, https://doi.org/10.1175/15200469(1980)037<2734:AMFTSA>2.0.CO;2, 1980.

Yang, J., Jiang, L., Ménard, C. B., Luojus, K., Lemmetyinen, J., and Pulliainen, J.: Evaluation of snow products over the Tibetan Plateau, Hydrol. Process., 29, 3247-3260, https://doi.org/10.1002/hyp.10427, 2015.
Zoogman, P., Liu, X., Suleiman, R. M., Pennington, W. F., Flittner, D. E., Al-Saadi, J. A., Hilton, B. B., Nicks, D. K., Newchurch, M. J., Carr, J. L., Janz, S. J., Andraschko, M. R., Arola, A., Baker, B. D., Canova, B. P., Chan Miller, C., Cohen, R. C., Davis, J. E., Dussault, M. E., Edwards, D. P., Fishman, J., Ghulam, A., González Abad, G., Grutter, M., Herman, J. R., Houck, J., Jacob, D. J., Joiner, J., Kerridge, B. J., Kim, J., Krotkov, N. A., Lamsal, L., Li, C., Lindfors, A., Martin, R. V., McElroy, C. T., McLinden, C., Natraj, V., Neil, D. O., Nowlan, C. R., O’Sullivan, E. J., Palmer, P. I., Pierce, R. B., Pippin, M. R., Saiz-Lopez, A., Spurr, R. J. D., Szykman, J. J., Torres, O., Veefkind, J. P., Veihelmann, B., Wang, H., Wang, J., and Chance, K.: Tropospheric emissions: Monitoring of pollution (TEMPO), J. Quant. Spectrosc. Ra., 186, 17-39, https://doi.org/10.1016/j.jqsrt.2016.05.008, 2017. 